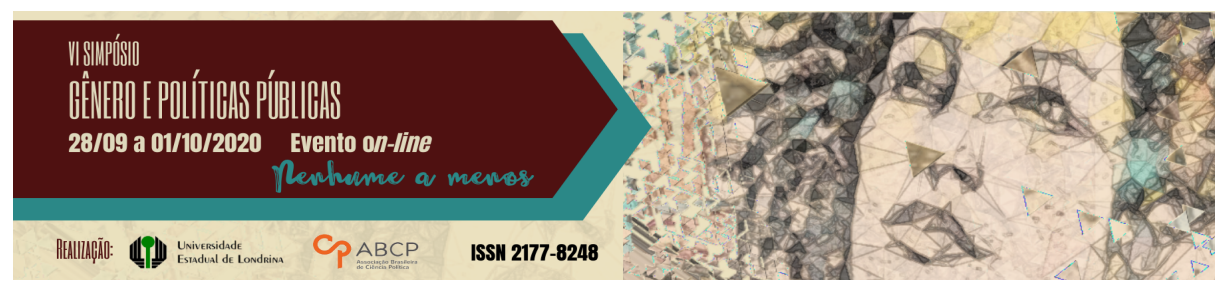

\title{
A importância da abordagem dos direitos humanos nas políticas públicas voltadas para a igualdade de gênero desde a infância: reflexões baseadas em casos de casamento infantil, gravidez precoce e trabalho infantil doméstico no Brasil
}

\author{
Thaís Nascimento Dantas ${ }^{1}$
}

\begin{abstract}
Resumo
Com base nos conceitos de pobreza multidimensional, feminização da pobreza e vulnerabilidades infantis, o artigo apresenta um breve resumo dos dados relativos às violações e desigualdades de gênero nos casos de casamento precoce, gravidez na adolescência e trabalho infantil doméstico no país. O objetivo é trazer algumas evidências relacionadas às causas e consequências desses problemas, mostrar que as desigualdades sociais estão ligadas a gênero e começam na infância. Demonstra, como conclusão que, para superar tais desigualdades, o Brasil deve adotar o enfoque de direitos humanos nas políticas, com abordagem interseccional, para alcançar a igualdade social e deve considerar a alta vulnerabilidade de meninas e mulheres, caso contrário, haverá uma erosão da integridade do Estado de Direito.
\end{abstract}

Palavras-chave: gênero, infância, políticas públicas.

\footnotetext{
1 Graduada pela Faculdade de Direito da Universidade de São Paulo. Pós-graduada em Políticas Públicas para a Igualdade na América Latina pelo Conselho Latino Americano de Ciências Sociais (Clacso). Bolsista do Master em Estado de Direito e Democracia Constitucional, da Universidade de Genova. Estuda a construção da desigualdade de gênero desde a infância e os mecanismos para sua superação. Advogada, vicepresidente da Comissão de Direitos Infanto-juvenis da Ordem dos Advogados do Brasil de São Paulo (OAB-SP), coordenadora do Núcleo de Direitos da Criança e do Adolescente da Escola Superior de Advocacia de São Paulo (ESASP), e conselheira do Conselho Nacional dos Direitos da Criança e do Adolescente (Conanda). Contato: ndantas.thais@gmail.com.
}

GT 11 - Gênero, políticas de desenvolvimento e combate à pobreza 


\title{
The importance of human rights approach on public policies focused on gender equality since the childhood: reflections based on cases of child marriage, early pregnancy and domestic child labor in Brazil
}

\begin{abstract}
Based on concepts of multidimensional poverty, feminization of poverty and childhood vulnerabilities, the article presents a brief summary of data related to violations and gender inequalities on Brazilian childhood, regarding the cases of child marriage, early pregnancy and domestic child labor in the country. The objective is to bring some evidences related to causes and consequences of those problems, to show the social inequalities are connected which gender and they start in childhood. In order to overcome the gender inequality, Brazil must adopt a human rights approach on policies to achieve social equality and it should consider the high vulnerability of girls and women, otherwise, there would be an erosion of the integrity of the Rule of Law.
\end{abstract}

Key words: gender, childhood, public policies

\section{Introdução}

O presente trabalho tem como objetivo evidenciar a necessidade de adotar, no âmbito das políticas públicas para a igualdade, um enfoque de direitos humanos, especialmente atento à questão de gênero e infância, de maneira interseccional, a partir de uma análise do cenário brasileiro.

Para tanto, inicialmente, será apresentado o conceito do enfoque de direitos humanos em políticas públicas e demonstrada sua importância especialmente em contextos de vulnerabilidade da infância, pobreza multidimensional e feminização da pobreza.

Em seguida, será apresentado um panorama de dados relacionados a violações de direitos que evidenciam a existência e a gravidade da desigualdade de gênero desde o começo da vida, em relação aos casos do casamento precoce, gravidez na adolescência e trabalho infantil doméstico, problemas que são endêmicos no país e 
trazem importantes reflexões sobre a construção do papel da mulher e sobre a pobreza intergeracional.

Dado que tais problemas contribuem para a reprodução de desigualdades, especialmente em relação gênero e pobreza, busca-se demonstrar a necessidade de fortalecer políticas públicas nas referidas temáticas e, mais do que isso, adotar um enfoque de gênero de maneira interseccional, a fim de construir estratégias aptas a contribuir para a superação das desigualdades, bem como implementar normativas incorporadas pelo Estado de Direito brasileiro.

\section{Um breve olhar para a pobreza de crianças e adolescentes brasileiros}

Revisões bibliográficas revelam que estudos sobre pobreza têm três vertentes principais ao delimitar o conceito de pobreza: uma que se relaciona à renda indispensável capaz de satisfazer exclusivamente as necessidades de caráter nutricional, denominada de linha de indigência ou de pobreza extrema; outra que se relaciona a necessidades básicas individuais, como saúde, educação, habitação, transporte, que extrapola questões relativas à alimentação e introduz um caráter multidimensional; e outra denominada enfoque das capacidades, o qual associa a pobreza às privações de necessidades básicas sofridas pelos indivíduos, na inexistência de oportunidades para se realizar alguns níveis mínimos de funcionamentos, que vão desde questões fundamentais de como estar bem nutrido, possuir uma boa saúde até questões mais complexas como ser feliz, possuir respeito próprio e participação na vida social.

Estudo do Fundo das Nações Unidas para a Infância (UNICEF, 2018) aponta que é fundamental olhar para o tema considerando as múltiplas violações envolvidas e apresenta dados preocupantes acerca da massiva incidência da pobreza em crianças e adolescentes: 6 em cada 10 vivem na pobreza - seja por serem pobres desde uma perspectiva financeira, seja por estarem privados de um ou mais direitos, como os 
de educação, informação, água, saneamento, moradia e proteção contra o trabalho infantil.

O mesmo documento alerta que, aqui, mais de 18 milhões de crianças e adolescentes, o equivalente a cerca de $34 \%$ do total, vivem em domicílios com renda per capita insuficiente para adquirir uma cesta básica de bens e que quase 27 milhões de crianças e adolescentes, o que corresponde a quase $50 \%$ do total, têm um ou mais direitos negados.

É importante adotar esse olhar complexo para a pobreza e entender os enlaces entre as duas abordagens - a financeira e a de privações múltiplas -, dado que, por exemplo, focar em estratégias de transferência de renda, sem contemplar a garantia de direitos, tende a trazer respostas limitadas à proteção da infância e adolescência. Diante disso, é sintomático que, no país, embora a pobreza monetária tenha sido reduzida na última década, as violações e privações não foram reduzidas na mesma proporção (UNICEF, 2018, p. 6). Em outras palavras, é dizer: o país não está sendo capaz de garantir os direitos de crianças e adolescentes com plenitude, ainda que tenha avançado na geração de renda. Ainda, importante salientar que isso se insere em um contexto de extremas desigualdades.

Aliados à enorme concentração de renda, que faz com que os seis brasileiros mais ricos tenham a mesma riqueza que os $50 \%$ mais pobres da população (OXFAM, 2017), verifica-se um maior contingente de pessoas negras pobres como uma das várias consequências nefastas do racismo estrutural2 $^{2}$ (ALMEIDA, 2019), aliado com uma maior incidência do problema social em mulheres, que, quando crescente, indica preocupante processo de feminização da pobreza ${ }^{3}$. Nesse contexto, é

\footnotetext{
2 Silvio de Almeida que o racismo em nossa sociedade é regra, e não exceção, pois está na sua estrutura: assim, as ordens econômica, política e social se organizam a partir de tal premissa e geram reflexos nas diversas instituições e práticas sociais.

3 O conceito "feminização da pobreza" foi introduzido por Diane Pearce, a qual afirma que "a pobreza está rapidamente se tornando um problema feminino", o que ela constata diante do aumento na proporção de famílias pobres chefiadas por mulher. Seu foco, incialmente é entender quais são as consequências econômicas e sociais de ser mulher sem o apoio de um marido e que acabam por conduzir à pobreza. Ainda, revisão bibliográfica aponta que há seis definições possíveis do que seja feminização da pobreza,
} 
importante ressaltar como raça e classe se interlaçam na geração de pobreza, desigualdade e vulnerabilidade social:

Mantendo a trajetória histórica marcada pelo racismo patriarcal que estrutura a sociedade brasileira, os dados disponíveis mostram mulheres, população negra, crianças, adolescentes e jovens como principais vítimas das injustas políticas adotadas pelos governos federal e das unidades federativas. A Síntese de Indicadores Sociais do IBGE ressalta que $72,7 \%$ das pessoas pobres no Brasil - 38,1 milhões são pretas ou pardas. As mulheres pretas ou pardas compõem o maior contingente de pessoas abaixo da linha da pobreza: somando 27,2 milhões de brasileiras vivendo com menos de $\mathrm{R} \$ 350$ por mês (GRUPO DE TRABALHO DA SOCIEDADE CIVIL PARA A AGENDA 2030, 2020, p. 11).

Assim, salienta-se a importância de uma abordagem interseccional para o problema, partindo do entendimento de que as opressões são múltiplas e complexas e de que não é possível compreender as desigualdades quando se analisa uma variável isoladamente, sendo preciso considerar os diversos marcadores sociais (BIROLI, MIGUEL, 2015), além de quais e como condições estruturais atravessam corpos (AKOTIRENE, 2019, p. 43) ${ }^{4}$.

Merece também destaque a transmissão intergeracional da pobreza, dado que o risco de pobreza entre crianças tem crescido ao

sendo elas: (i) aumento da proporção de mulheres entre os pobres; (ii) aumento da proporção de pessoas em famílias chefiadas por mulheres entre os pobres; (iii) aumento absoluto na incidência ou na intensidade da pobreza entre as mulheres; (iv) aumento nos diferenciais de incidência ou de intensidade da pobreza entre mulheres e homens; (v) aumento na incidência ou na intensidade da pobreza entre as pessoas de famílias chefiadas por mulheres; e (vi) aumento nos diferenciais de incidência ou de intensidade da pobreza entre as pessoas de famílias chefiadas por mulheres e de famílias chefiadas por homens (IPEA, 2005).

4 "A interseccionalidade impede aforismos matemáticos hierarquizantes ou comparativos. Em vez de somar identidades, analisa-se quais condições estruturais atravessam corpos, quais posicionalidades reorientam significados subjetivos desses corpos, por serem experiências modeladas por e durante a interação das estruturas, repetidas vezes colonialistas, estabilizadas pela matriz de opressão, sob a forma de identidade". 
longo do tempo. Aliado a isso, tem-se uma preocupação com a mobilidade social e com a elasticidade intergeracional de renda, dado que o nível de rendimento dos filhos é fortemente influenciado pelo dos pais quando não há políticas que ampliem a possibilidade de ascensão social, como no caso brasileiro, em que o país ocupa a segunda pior posição no âmbito de mobilidade social e em que, em média, são necessárias nove gerações para que os descendentes de um brasileiro entre os $10 \%$ mais pobres atinjam o nível médio de rendimento do país (OECD, 2018).

Evidente, portanto, que para superar a pobreza e a desigualdade é preciso olhar com atenção à infância.

\section{A desigualdade tem gênero e começa na infância: um olhar para casamento infantil, gravidez precoce e trabalho infantil doméstico}

Apresenta-se aqui, sucintamente, informações relacionadas a casamento infantil, gravidez precoce e trabalho infantil doméstico. Vale salientar que a escolha de tais fenômenos tem duas justificativas principais: além de terem grande incidência no país entre meninas, trazem importantes reflexões sobre papeis de gênero e transmissão intergeracional de pobreza.

\section{Casamento precoce}

O casamento precoce $^{5}$ é entendido como a união na infância e adolescência ${ }^{6}$, formal ou informal, com adultos ou indivíduos de idade inferior a dezoito anos. A análise da incidência desse problema e de seus

\footnotetext{
${ }^{5}$ De maneira semelhante, para referir-se ao mesmo fenômeno, são utilizados os termos "casamento infantil" e "casamento forçado".

6 Pela legislação brasileira, é considerada criança a pessoa com idade inferior a 12 anos de idade, e adolescente aquela com idade entre 12 e 18 anos, conforme artigo $2^{\circ}$ da Lei 8.069 de 1990 (Estatuto da Criança e do Adolescente). Destaque-se que, no direito internacional, é considerada criança toda pessoa com até 18 anos de idade, por força da Convenção sobre os Direitos da Criança, da qual o Brasil é signatário e incorporou ao seu ordenamento jurídico por meio do Decreto 99.710 de 1990.
} 
efeitos sociais evidenciam que o casamento precoce tem consequências gravosas para o agravamento de vulnerabilidades e desigualdades.

O casamento precoce é um desafio mundial: a cada ano, 15 milhões de meninas em todo o mundo se casam antes dos 18 anos e a projeção é que esse índice evolua para 18,5 milhões até 2050 (UNICEF, 2014, p. 6). A situação se reproduz, também de maneira massiva, no Brasil: segundo o Censo de 2010, aproximadamente 88 mil meninas e meninos com idades entre 10 e 14 anos estão em uniões consensuais, civis e/ou religiosas (TAYLOR et al, 2015, p. 10), dados que colocam o país em primeiro lugar na América Latina e em quarto lugar no mundo em incidência de casamento precoce. Sua ocorrência está relacionada a violações aos direitos à educação, à saúde e à integridade (idem, p. 18), os quais são assegurados prioritariamente a crianças e adolescente, por força constitucional.

No que toca à educação, o casamento precoce é responsável por cerca de $30 \%$ do abando no escolar feminino e resulta em um nível educacional mais baixo para meninas (UNICEF, 2014, p. 4). Em relação à saúde, meninas casadas têm menos chances de receber cuidados médicos durante a gravidez e maior risco de complicações graves (TAYLOR et al, 2015, p. 104); além disso, o casamento precoce responde pelas taxas mais altas de mortalidade materna e infantil (UNICEF, 2014, p. 6). Por fim, em violação à integridade, a violência doméstica mostra-se frequente: meninas que casam têm probabilidade $22 \%$ maior de sofrer violência de seu parceiro íntimo do que mulheres adultas (KLUGMAN et al, 2014, p. 77), o que é especialmente preocupante se considerarmos que são estes os agressores mais comuns (OMS, 2002, p. 89).

Verifica-se, portanto, que o casamento precoce é multifatorial e impacta os direitos de crianças e adolescentes de maneira gravosa. Tal como ocorre mundialmente, o casamento 
precoce no Brasil afeta majoritariamente meninas, o que demonstra uma desigualdade decorrente do gênero (TAYLOR et al, 2015, p. 11) no âmbito dos casamentos precoces.

Ainda, este fenômeno, no contexto brasileiro, guarda uma peculiaridade: ao contrário de outros países que também apresentam elevados índices de casamento precoce, as uniões no Brasil não são forçadas, e sim apresentadas como consensuais, além de informais, sendo, segundo a mesma autora, uma das principais razões do casamento precoce, ao lado do controle da sexualidade feminina, a busca por segurança financeira.

\section{Gravidez na adolescência}

Em 2015, o número total de mães adolescentes entre 10 e 19 anos totalizava 545.537 no Brasil - o equivalente a 18,1\% dos nascidos vivos no período (PLAN, 2017, p. 37). Em casos de gravidez precoce, há elevados índices de mortalidade materna e infantil, além de baixo peso dos bebês ao nascer (MINISTÉRIO DA SAÚDE, 2013) e, entre os fatores que podem explicar esses números, estão a ausência e insuficiência de consultas pré-natal, que geram baixa cobertura de vacina antitetânica e alto número de sífilis congênita, além da realização de muitos partos cesáreos.

São diversas as causas da gravidez em adolescentes no Brasil (UNICEF, 2017, p. 13): descompasso entre o desejo sexual e o risco de gravidez, vontade da maternidade, necessidade de mudança de status social, e violência sexual, aliados aos contextos normativo e institucional, relacionados ao status das leis e de sua fiscalização, das políticas públicas sociais, bem como a fatores estruturantes/transversais, que dizem respeito a concepções e normas sociais relativas à adolescência, sexualidade, casamento e gravidez, as quais estruturam preferências, comportamentos, atitudes e práticas sociais das crianças e adolescentes, de seus familiares e dos profissionais 
e agentes que realizam a intervenção social junto às meninas e adolescentes grávidas 7 .

O mesmo relatório aponta que é fundamental considerar os custos econômicos e no desenvolvimento pessoal, dado que metade das meninas que engravidam de maneira indesejada evadem das escolas e depois o baixo nível educacional dificulta a sua inserção no mercado de trabalho e lhes impede de ascender a empregos de qualidade e lhes submete frequentemente a empregos informais. Mais uma vez, verificase o impacto da gravidez na condição econômica de meninas.

\section{Trabalho infantil doméstico}

O termo trabalho infantil doméstico contempla toda prestação de serviços continuada, remunerada ou não, realizada para terceiros ou para a própria família que, pelas condições em que são executadas, viola direitos de crianças e adolescentes à vida, à saúde, à educação, ao brincar, ao lazer, à profissionalização, ao desenvolvimento integral e a viver uma vida livre de violência (FNPETI, 2018, p. 15).

O trabalho infantil doméstico demonstra a profunda relação entre gênero e vulnerabilidades. Segundo o Fórum Nacional de Prevenção e Erradicação do Trabalho Infantil (idem, p. 21), são as meninas negras, pobres e procedentes de áreas periféricas ou rurais que ocupam as funções domésticas remuneradas ou não, em suas residências ou de terceiros. Em 2015, 2,7 milhões de pessoas de 5 a 17 anos estavam trabalhando. Em números absolutos há mais meninos trabalhando $(65,5 \%$ do total) do que meninas $(34,5 \%)$. No entanto, o trabalho doméstico, considerado uma das piores formas de trabalho infantil segundo a Organização Internacional do Trabalho, é realizado quase pela totalidade das meninas que trabalham (94,1\%). Ainda, 58,9\% das crianças e adolescentes trabalhadores ainda se ocupam dos afazeres

\footnotetext{
7 Embora não seja o objeto do presente artigo, fundamental considerar, também, as dificuldades no acesso ao direito a aborto legal e seguro, mesmo em caso de meninas que têm gestação fruto de violência sexual e/ou que impõe riscos à saúde.
} 
domésticos, para além do trabalho que realizam - isto é, exercem dupla jornada de trabalho, mais a escola - sendo a maioria meninas: $17,9 \%$ das meninas que trabalham exercem o trabalho doméstico de caráter profissional na casa de terceiros, contra 0,6\% dos meninos (FNPETI, 2015). A maioria das meninas ocupadas no trabalho infantil domésticos são negras $(73,4 \%)$. Em relação à ocupação infantil total, o trabalho infantil doméstico é maior entre crianças negras, com 7,9\%, do que entre as não negras, com 4,8\%. O percentual de crianças e adolescentes inseridos no trabalho infantil no Brasil vem decaindo ao longo dos últimos 20 anos. Entre 1992 e 2014, o percentual caiu em 57,1\%, com 4,4 milhões crianças a menos trabalhando (PNAD, 2015). Apesar da tendência geral de queda, na faixa etária de 5 a 13 anos o trabalho infantil vem crescendo. No total, são 412 mil crianças trabalhando nessa faixa etária, sendo que 79 mil estavam na faixa entre 5 e 9 anos e $333 \mathrm{mil}$ na faixa de 10 a 13 anos. No entanto, os desafios ainda permanecem quanto às piores formas, dentre elas o trabalho infantil doméstico, majoritariamente feminino.

Como desde a infância meninas são imbuídas de tarefas e padrões sobre trabalhos domésticos, há uma assimilação carregada por toda a vida sobre isso. Mulheres são relegadas ao ambiente doméstico e responsabilizadas pelo cuidado e pela manutenção de condições básicas para o bom funcionamento e desenvolvimento individual dos companheiros, filhos e familiares. Essa partilha desigual de responsabilidades domésticas - ou, como cada vez mais se tem alertado, esse trabalho de cuidado não remunerado - além de limitar o papel da mulher na sociedade, tem impactos extremamente negativos nas oportunidades educacionais e empregatícias que meninas acessam - o que, também, traz impactos limitados para sua ascensão econômica (FNPETI, 2015).

Casamento precoce, gravidez na adolescência e trabalho doméstico infantil como violações a normas de proteção a meninas 
A breve apresentação de dados sobre casamento e gravidez precoces, bem como acerca do trabalho infantil doméstico, evidenciam uma relação de tais fenômenos com a desigualdade de gênero, bem como apontam a pobreza como uma das principais causas de tais problemas, ao mesmo tempo em que estes geram o agravamento da vulnerabilidade socioeconômica de meninas e famílias, com repercussão quase determinante na restrição de sua ascensão social.

Nesse contexto, relevante apurar como tais fenômenos dialogam com as normativas adotadas pelo Brasil, a fim de evidenciar a responsabilidade estatal de enfrentar tais problemas sociais, inclusive por meio de políticas públicas.

Inicialmente, importante considerar que o Brasil tem, em seu direito interno, uma previsão constitucional, no artigo 227 , voltada à proteção de crianças e adolescentes com absoluta prioridade, bem como um diploma específico para tutelar direitos assegurados à infância e adolescência. Trata-se do Estatuto da Criança e do Adolescente, que, além de fixar a não discriminação de crianças e adolescentes, estabelece que tais indivíduos devem estar em primeiro lugar no âmbito de políticas, serviços e orçamento público.

A Constituição Federal reconhece, também, em seu artigo $5^{\circ}$, que homens e mulheres são iguais em direitos e obrigações. Ainda, destacam-se leis nacionais protetivas a mulheres: a Lei Maria da Penha, que tornou crime a violência doméstica e familiar contra a mulher; a Lei do Feminicídio, que estabeleceu penas mais rigorosas em assassinatos femininos que envolvam violência doméstica e familiar ou menosprezo e discriminação à condição de mulheres; a Emenda Constitucional das Domésticas, que regulamentou o trabalho doméstico; e a Lei da Profilaxia da Gravidez, que determina o atendimento imediato e obrigatório a pessoas vítimas de violência sexual no Sistema Único de Saúde (SUS).

Vale ainda ressaltar a regulação jurídica nos temas de casamento e gravidez precoces e trabalho infantil. 
O Código Civil Brasileiro, ao tratar da capacidade para o casamento $^{8}$, estabelece como idade mínima os dezoito anos ${ }^{9}$, porém permite o casamento a partir dos dezesseis anos, desde que haja expressa autorização de ambos os pais ou responsáveis, o que, em caso de discordância, pode vir a ser suprido judicialmente. Antes, havia outras exceções. Até o início de 201910, em caso de gravidez ${ }^{11}$, o casamento era permitido em qualquer idade. Até 2005, havia outra exceção, também já revogada12, a qual autorizava o casamento para evitar imposição ou cumprimento de pena criminal, notadamente nos casos de violência sexual. Ainda, não é prevista nenhuma forma de responsabilização aplicável àqueles que autorizam, realizam ou contraem casamento em desrespeito à lei, diferentemente do que ocorre em outros países na região latino-americana - o que é considerado um instrumento essencial para reduzir a impunidade e possibilitar a reparação (SAKHONCHIK et al, 2017, p. 1).

No que toca à gravidez precoce, importante considerar que a idade fixada para a constatação do estupro de vulnerável é de 14 anos, conforme artigo 217-A do Código Penal Brasileiro. Ainda, a Lei nº 13.798 de 2019 instituiu novo artigo no Estatuto da Criança e do Adolescente e criou a Semana Nacional de Prevenção da Gravidez na Adolescência.

Em relação ao trabalho infantil, é proibido qualquer trabalho aos menores de 16 anos, exceto na condição de aprendiz, que pode ser exercida a partir dos 14 anos, sendo também vedado o trabalho noturno,

\footnotetext{
8 Vide Capítulo II - Da Capacidade para o Casamento, artigos 1.517 a 1.520 do Código Civil Brasileiro.

${ }^{9}$ Ao refletir sobre a idade limite é necessário considerar algumas nuances. Seria 18 anos o limite etário adequado, considerando que a idade fixada para a constatação do estupro de vulnerável é de 14 anos, conforme artigo 217-A do Código Penal Brasileiro? É possível pensar em exceções relacionadas à diferença de idade entre os indivíduos do casal, em semelhança ao instituto norte-americano de exceção de Romeu e Julieta, que afasta a presunção de violência quando a diferença de idade seja igual ou menor de cinco anos? (COLVARA, 2014, p. 35).

10 Por meio da Lei 13.811 de 2019.

11 Por esta previsão legal, depreende-se que apenas meninas podem se casar antes dos 16 anos, enquanto meninos não podem, tendo em vista que somente estas podem engravidar, o que tornava a previsão legal discriminatória (TAYLOR et al, 2015, p. 28).

12 Por meio da Lei 11.106 de 2005, que alterou o artigo 107 do Código Penal.
} 
perigoso ou insalubre aos menores de 18 anos, conforme previsão do artigo $7^{\circ}$, inciso XXXIII, da Constituição Federal. Ainda, os artigos 60 a 69 do Estatuto da Criança e Adolescente, em complemento ao texto constitucional, regulam a profissionalização e proteção no trabalho. Não há, entretanto, nenhuma previsão específica em relação ao trabalho infantil doméstico, especialmente de meninas.

Cabe ainda mencionar a adesão brasileira a documentos normativos internacionais que asseguram direitos com um olhar atento especificamente a crianças, adolescentes, meninas e mulheres, dentre os quais destacam-se: Pacto Internacional sobre Direitos Econômicos, Sociais e Culturais, Convenção sobre os Direitos da Criança, Convenção para a Eliminação de Todas as Formas de Discriminação contra a Mulher, Declaração de Viena, Declaração de Cairo, Declaração e Plataforma de Ação de Pequim, Declaração e Plano de Ação de Durban e a Agenda 2030 para o Desenvolvimento Sustentável que, em seu objetivo cinco, prevê de maneira específica alcançar a igualdade de gênero e empoderar todas as mulheres e meninas, e estabelece metas concretas no que toca à erradicação de casamentos infantis, no reconhecimento de trabalho doméstico e na garantia de direitos reprodutivos e sexuais, dentre outros.

Embora identifiquem-se avanços na proteção jurídica de meninas e mulheres, verifica-se que a legislação não considera adequadamente a desigualdade de gênero, dado que não prevê mecanismos de responsabilização no caso de casamento precoce, que a lei da semana de prevenção da gravidez precoce traz poucas ações concretas que não tem se revertido, de maneira concreta, em ações de educação sexual e acesso a direitos sexuais e reprodutivos por meninas e que, no âmbito do trabalho infantil, o trabalho infantil doméstico é frequentemente invisibilizado.

Nesse sentido, entende-se estar diante de uma situação de desrespeito oficial (POGGE, 2008, p. 65), em que o governo e seus agentes e agências violam os direitos humanos, emitindo ou mantendo leis injustas ou ordens que autorizem ou exijam violações de direitos 
humanos, ou quando não há proteção correta, por meio de políticas públicas, por exemplo.

Construindo soluções aos impactos da desigualdade de gênero na infância a partir do enfoque de direitos humanos em políticas públicas

Inicialmente, cabe estabelecer que o presente trabalho adota o conceito de política pública como programa de ação governamental (BUCCI, 2008, p. 227), ou seja, o meio por qual o Estado atua para atender o interesse público e satisfazer direitos.

Explicita-se, também, que o enfoque de direitos humanos em políticas públicas concebe direitos humanos de uma maneira integral, interdependente e complementar, além de focar na concretização e materialização de tais direitos, especialmente em relação a grupos marginalizados ou em condição de vulnerabilidade, o que ocorre por meio de políticas públicas temáticas. Relevante salientar que o enfoque de direitos humanos é resultado de processos políticos e sociais a nível global e regional de lutas por direitos. Nesse contexto, as gerações de direitos representam um processo histórico de ampliação do conteúdo jurídico da dignidade humana, bem como o Direito passa a ser entendido como um instrumento para consecução de determinados objetivos (BENITEZ, 2007). Com tal abordagem, implica0se a revalorização do Direito como instrumento de integração social, de maneira que criam-se mecanismo institucionais para sua exigibilidade (ABRAMOVICH, 2016).

Importante considerar que, nessa perspectiva tal abordagem permite enfrentar desigualdades estruturais presentes na sociedade, tais como o adulto centrismo e o sexismo, que nos parecem pontos centrais para o enfrentamento às questões ora apresentadas, sobre casamento e gravidez precoces, e trabalho infantil doméstico. 
Em síntese, políticas públicas com enfoque de direitos humanos caracterizam-se pelo fato de:

Armonizar los principios de derechos humanos y las obligaciones del Estado con el marco de acción propuesto por los hacedores de políticas. Es decir, se trata de asegurar que las políticas de desarrollo no entren en contradicción con los principios fundamentales de los derechos humanos, como la universalidad, la indivisibilidad, la interdependencia y, entre otros, la no discriminación, y que además se promuevan acciones afirmativas tendientes a garantizar los derechos de la población, en especial para los sujetos y grupos en peor situación de indefensión. Expresado en otros términos, se trata de asegurar que las políticas públicas se constituyan en una herramienta para la realización de los derechos humanos de las personas para las que se diseñan e implementan (MURCIA, 2012, p. 59) ${ }^{13}$.

Para fins de sistematização, é possível afirmar que a abordagem dos direitos humanos tem os seguintes elementos no campo das políticas públicas: (i) toda política pública deve ter os direitos humanos como base, porque é sua razão legitimadora; (ii) os direitos humanos devem ser considerados indivisíveis, interdependentes e não hierarquizados; (iii) os direitos humanos devem ser considerados em uma concepção progressista e aberta, ou seja, não se pode aceitar retrocessos e quando a interpretação e o alcance dos direitos são ampliados por órgãos internacionais, isso deve ser considerado nacionalmente nas políticas públicas; (iv) os cidadãos devem ter poderes para reconhecer a importância de sua participação e as formas de participação; (v) os

\footnotetext{
13 Em tradução livre: "Harmonizar os princípios dos direitos humanos e as obrigações do Estado com a estrutura de ação proposta pelos formuladores de políticas. Em outras palavras, trata-se de garantir que as políticas de desenvolvimento não contrariem os princípios fundamentais dos direitos humanos, como universalidade, indivisibilidade, interdependência, não discriminação, e que ações afirmativas também sejam promovidas. Visa garantir os direitos da população, especialmente dos sujeitos e grupos em pior situação de indefesa. Trata-se de garantir que as políticas públicas se tornem um instrumento de efetivação dos direitos humanos das pessoas para as quais foram concebidas e implementadas".
} 
mecanismos de participação devem ser assegurados para assegurar a participação social durante a elaboração, implementação e avaliação de políticas públicas e a decisão popular deve ter um efeito vinculante; (vi) transparência, prestação de contas, dados do desempenho público e indicadores devem ser assegurados para viabilizar o controle social; (vii) a abordagem de gênero precisa ser considerada para assegurar a paridade, os direitos sexuais e reprodutivos, a conciliação entre vida profissional e pessoal e uma vida livre de violência; e (viii) uma abordagem interseccional, o que significa que a desigualdade de gênero deve ser considerada em conjunto com outras vulnerabilidades, como raça, etnia, classe, idade, deficiência, questões LGBTI e assim por diante. A abordagem dos direitos humanos deve ser introduzida em todas as políticas públicas, durante todo o processo, desde a elaboração até a implementação e avaliação, como pressuposto que orienta todas as escolhas e estratégias públicas.

Tendo em vistas as consequências gravosas do casamento infantil, da gravidez precoce e do trabalho infantil doméstico, que impactam negativamente meninas desde a infância, entende-se que o desenvolvimento de políticas públicas temáticas é essencial e, em verdade, é uma condição para a superação da desigualdade de gênero no país.

\section{Considerações finais.}

Entende-se que é preciso ter em mente que, para superar desigualdades e pobreza, é fundamental atentar para a infância e começar a construir caminhos mais igualitários desde o começo da vida de meninas e meninos. O Estado deve assegurar políticas públicas com disponibilidade orçamentária focadas na construção da igualdade de gênero, atentando para a educação, para a construção de meios de acesso igualitário a serviços e direitos, e para o combate a violações.

Esta preocupação mostra-se central se considerarmos que a norma da absoluta prioridade da criança e do adolescente, assegurada 
internacionalmente pela Convenção sobre os Direitos da Criança, bem como nacionalmente pela Constituição Federal, e disciplinada pelo Estatuto da Criança e do Adolescente, garante também preferência da infância e adolescência nas políticas sociais públicas e orçamento privilegiado para sua execução ${ }^{14}$.

E não se tratam de quaisquer políticas públicas - devem ser iniciativas com enfoque de direitos humanos e abordagem interseccional, dado que as evidências trazidas apontam que este é o caminho mais eficiente e que o país já se comprometeu com isso no campo normativo.

Um dos pontos centrais do conceito de Estado de Direito é que indivíduos têm direito à igualdade; nesse sentido, a profunda e persistente iniquidade econômica - atualmente atrelada indubitavelmente às desigualdades de gênero e raça - impacta negativamente a integridade do Estado de Direito (VIEIRA, 2008, p. 33).

Assim, no caso dos direitos de crianças e adolescentes, em decorrência do cenário normativo apresentado (SILVEIRA; VERONESE, 2015, p. 129), entende-se que o investimento em políticas públicas para esse público - especialmente visando à superação de casamento precoce, gravidez na adolescência e trabalho infantil doméstico - é mandatório.

\section{Referências}

ABRAMOVICH, Victor. Una aproximación al enfoque de derechos en las estrategias y políticas de desarrollo. Revista de la Cepal, 2006. Disponível

em:

14 Nesse sentido: "No que tange à possibilidade de o Poder Judiciário intervir na formulação de políticas públicas para determinar a concretização de direitos fundamentais prestacionais relativos a crianças e adolescentes, a jurisprudência pátria, com alguma exceção, tem reconhecido essa possibilidade, sob o argumento de que os princípios constitucionais têm força normativa e irradiam efeitos concretos. A inobservância desses princípios-garantia por parte do Administrador Público configura omissão inaceitável e pode ser reparada pelo Poder Judiciário" (FREITAS, 2014, p. 141). 
https:/ / repositorio.cepal.org/bitstream/handle/11362/11102/1/08 8035050_es.pdf. Acesso em: 30 ago. 2020.

AGUILAR, P. L. La feminización de la pobreza: conceptualizaciones actuales y potencialidades analíticas. Revista Katál, v. 14, n. 1, p. 126133, jan./jun. 2011.

AKOTIRENE, Carla. Interseccionalidade. São Paulo: Ed. Pólen, 2019.

ALMEIDA, Silvio Luiz de. Racismo Estrutural. São Paulo: Ed. Pólen, 2019.

ARRIAGADA, I. Dimensiones de la pobreza y políticas desde una perspectiva de género. Revista de la CEPAL, n. 85, p. 101-113, 2005.

BENITEZ, W.G.J. El Enfoque de los Derechos Humanos y las Políticas Públicas. Univ. Sergio Arboleda. 2007. Disponível em: https:/ / revistas.usergioarboleda.edu.co/index.php/ccsh/article/vi ew/781. Acesso em: 06 abr. 2020.

BIROLI, F.; MIGUEL, L. F. Gênero, raça, classe: opressões cruzadas e convergências na reprodução das desigualdades. Mediações, v. 20, n. 2, p. 27-55, jul./dez. 2015.

BIROLI, Flávia. Democracia e tolerância à subordinação: livre-escolha e consentimento na teoria política feminista. Rev. Sociol. Polit., v. 21, n. 48, p.127-142, 2013.

BUCCI, Maria Paula Dallari. Notas para uma metodologia jurídica de análise de políticas públicas. In: DIAS; ESTEVES; FORTINI (Org.). Políticas públicas: possibilidades e limites. Belo Horizonte: Fórum, 2008. p. 225-260.

COLVARA, Gabriel. A exceção de Romeu e Julieta: Uma análise sobre a compatibilidade do instituto norte americano com o ordenamento jurídico nacional. 2014. Trabalho de Conclusão de Curso (graduação em Direito) - Universidade Federal de Santa Catarina, Florianópolis, 2014.

COMISSÃO ESPECIAL DO TRABALHO INFANTIL DOMÉSTICO. Proposta de Estratégia de Prevenção e Erradicação do Trabalho Infantil Doméstico e Proteção da Adolescente Trabalhadora. 2015.

CONAETI. Plano Nacional de Prevenção e Erradicação do Trabalho Infantil e Proteção ao Adolescente Trabalhador. 2004. 
COSTA, J. S.; PINHEIRO, L.; MEDEIROS, M.; QUEIROZ, C. A face feminina da pobreza: sobre-representação e feminização da pobreza no Brasil. Texto para Discussão, n 1137. Brasília: IPEA, 2005.

CRENSHAW, Kimberlé Williams. Intersectionality, Identity Politics, and Violence Against Women of Color. Stanford Law Review, n. 43, v. 6, p. 1241-1299, 1991.

DANTAS, T. et al. Trabalho infantil doméstico de meninas: construindo soluções a partir de um enfoque de gênero. In: ANDRADE, Sergio (Org.). Soluções para a implantação dos Objetivos de Desenvolvimento Sustentável. 2018.

ESCUDERO, Rafael. Los derechos colectivos frente al disparate y la barbarie. In: ANSUÁTEGUI ROIG, J. (Ed.) Una discusión sobre los derechos colectivos. Dykinson, Madrid 2001.

FARAH, M. F. S. Gênero e políticas públicas. Estudos feministas, v. 12, n. 1, p. 47-71, jan./abr. 2004.

FERRAJOLI, L. Pasado y futuro del estado de derecho. Revista Internacional de Filosofía Política, 17, p. 31-45, 2001.

FNPETI, MPT. Trabalho Infantil nos ODS. 2018. Disponível em: https:/ / www.chegadetrabalhoinfantil.org.br/wpcontent/uploads/2017/10/agenda_2030_e_trabalho_infantil.pdf. Acesso em: 31 ago. 2020.

FREITAS, Vanessa Dosualdo. Princípio constitucional da prioridade absoluta e sua densidade normativa: o neoconstitucionalismo e a superação do discurso programático dos direitos fundamentais prestacionais relativos a crianças e adolescentes. Revista Jurisvox, ano 15, n. 15, v. 1, 2014.

GRUPO DE TRABALHO DA SOCIEDADE CIVIL PARA A AGENDA 2030. IV Relatório Luz da Sociedade Civil da Agenda 2030 de Desenvolvimento Sustentável no Brasil. 2020. Disponível em: <https://actbr.org.br/uploads/arquivos/por_rl_2020_vs_4_mari_si nglepage.pdf>. Acesso em: 21 agosto 2020.

IPEA. A face feminina da pobreza: sobre-representação e feminização da pobreza no Brasil. 2005. Disponível em: http://www.ipea.gov.br/portal/images/stories/PDFs/TDs/td_113 7.pdf. Acesso em: 22 ago. 2020. 
KLUGMAN, Jeni et al. Voice and Agency: Empowering Women and Girls for Shared Prosperity. Washington, 2014.

MINISTÉRIO DA SAÚDE. Manual Instrutivo para a implementação da Agenda para intensificação da atenção nutricional à desnutrição infantil. Brasília, 2013.

MURCIA, L. E. P. Desarrollo, derechos sociales y políticas públicas. In: GARAVITO, C. R. et al. Los derechos sociales en serio: Hacia un diálogo entre derechos y políticas públicas. Bogotá, 2012.

NOVELLINO, M. S. F. Os estudos sobre feminização da pobreza e políticas públicas para mulheres. Encontro Nacional de Estudos Populacionais, XIV. Anais [...]. 2004.

OECD. O elevador social está quebrado? Como promover mobilidade social. 2018. Disponível em: https:/ / www.oecd.org/brazil/social-mobililty2018-BRA-PT.pdf. Acesso em: 21 ago. 2020.

OLIVEIRA, N. S. M. N; LIMA, J. F. Pobreza multidimensional das mulheres chefes de família da região nordeste. ENANPUR, XVIII, 2019. Anais [...]. 2019. Disponível em: http:/ / anpur.org.br/xviiienanpur/anaisadmin/capapdf.php?reqid =49. Acesso em: 02 ago. 2020.

ORGANIZAÇÃO MUNDIAL DA SAÚDE. World Report on Violence and Health. Genebra, 2002. Disponível em: https://www.unicef.org/media/files/Child_Marriage_Report_7_17 _LR..pdf. Acesso em: 17 jul. 2019.

OXFAM BRASIL. A distância que nos une: um retrato das desigualdades brasileiras. 2017. Disponível em: https://www.oxfam.org.br/umretrato-das-desigualdades-brasileiras/a-distancia-que-nos-une/. Acesso em: 21 ago. 2020.

PEREIRA, Jane Reis Gonçalves; GONÇALVES, Gabriel Accioly. Inconstitucionalidade Sistêmica e Multidimensional: Transformações no Diagnóstico das Violações à Constituição. Revista Juris Poiesis, ano 18, n. 18, p. 130-159, jan./dez. 2015.

PEREIRINHA, J. A. (Org.). Género e Pobreza: impacto e determinantes da pobreza no feminino. Lisboa, Comissão para a Cidadania e Igualdade de Género, 2008. 
PESQUISA NACIONAL POR AMOSTRA DE DOMICÍLIO (PNAD). Sintese de indicadores 2015. IBGE. Rio de Janeiro: 2016.

PLAN INTERNATIONAL BRASIL. As meninas e os Objetivos de Desenvolvimento Sustentável (ODS): uma análise da situação das meninas no Brasil. 2017.

POGGE, Thomas. How should human rights be conceived? Pogge, World Poverty and Human Rights. 2 ed. Polity Press, 2008. p. 58-76.

SAKHONCHIK, Alena; RECAVARREN, Isabel Santagostino; TAVARES, Paula. Fechando a brecha: melhorando as leis de proteção à mulher contra a violência. São Paulo, 2017.

SILVEIRA, Mayra; VERONESE, Josiane Rose Petry. Normas Constitucionais de Proteção à Criança e ao Adolescente: Uma questão de eficácia ou de desrespeito? In: VERONESE, Josiane Rose Petry; ROSSATO, Luciano Alves; LÉPORE, Paulo Eduardo. Estatuto da Criança e do Adolescente: 25 anos de desafio e conquistas. São Paulo, 2015.

TAYLOR, A.Y.; LAURO, G., SEGUNDO, M., GREENE, M.E. “Ela vai no meu barco": Casamento na infância e adolescência no Brasil. Rio de Janeiro, 2015. Disponível em: https://promundoglobal.org/wpcontent/uploads/2015/07/SheGoesWithMeInMyBoat_ChildAdoles centMarriageBrazil_PT_web.pdf. Acesso em: 17 ago. 2020.

UNICEF. Ending Child Marriage: Progress and Prospects. Disponível em: https://www.unicef.org/media/files/Child_Marriage_Report_7_17 _LR..pdf. Acesso em: 17 ago. 2020.

UNICEF. Gravidez na Adolescência no Brasil. 2017. Disponível em: https:/ / www.unicef.org/brazil/media/1896/file/Gravidez_na_Ad olescencia_no_Brasil.pdf. Acesso em: 17 agosto 2020.

UNICEF. Pobreza na Infância. Brasília, 2018. Disponível em: www.unicef.org/brazil/media/156/file/Pobreza_na_Infancia_e_na _Adolescencia.pdf. Acesso em: 02 ago. 2020.

VIEIRA, Oscar Vilhena. Inequality and the subversion of the Rule of Law. Sur, Revista internacional de direitos humanos, v. 4, n. 6, p.28-51, 2007. 